\title{
CONTROLE GENÉTICO DA EXIGÊNCIA TÉRMICA PARA O INÍCIO DO FLORESCIMENTO EM MILHO $\left({ }^{1}\right)$
}

\author{
JOSÉ LUIS LIMA $\left({ }^{2}\right)$; JOÃO CÂNDIDO DE SOUZA $\left({ }^{3}\right)$; JUAREZ CAMPOLINA MACHADO $\left({ }^{4}\right)$; \\ MAGNO ANTONIO PATTO RAMALHO $\left({ }^{3}\right)$
}

\begin{abstract}
RESUMO
O presente trabalho teve como objetivo estudar o controle genético da exigência térmica para o início do florescimento em milho. Foram utilizadas duas linhagens contrastantes para o caráter em questão. A partir dessas duas linhagens, foram obtidas as gerações $F_{1}, F_{2}, R_{1}$ e $R_{2}$. Os dados referentes aos valores de graus-dia compreendidos entre a semeadura e o início do florescimento, foram obtidos por planta. Estimaram-se os componentes de média e de variância por meio do método dos quadrados mínimos ponderados. Constatou-se que em todos os modelos dos componentes de média avaliados os valores de $\mathrm{R}^{2}$ foram próximos de $100 \%$. Dessa forma, considerou-se o modelo simplificado, denominado aditivo-dominante. Pelos componentes de variância, o modelo envolvendo a variância aditiva, variância de dominância e variância ambiental foi suficiente para explicar o controle genético do florescimento em milho, evidenciando que a soma térmica como medida da precocidade em milho é oligogênica, com a presença de dominância. $O$ alto valor da estimativa do coeficiente de herdabilidade permite inferir a possibilidade de sucesso com a seleção massal para o caráter.
\end{abstract}

Palavras-chaves: Zea mays L., componentes genéticos, herdabilidade.

\section{ABSTRACT \\ GENETIC CONTROL OF THE THERMAL DEMAND FOR FLOWERING INITIATION IN MAIZE}

The objective of this work was to study the genetic control of thermal demand for maize flowering initiation. Two contrasting lines were crossed and used with the $\mathrm{F}_{1}, \mathrm{~F}_{2} \mathrm{RC}_{1}$ and $\mathrm{RC}_{2}$ derived populations. The trait day-degrees between sown and flowering per plant were evaluated to obtain the estimates of components of variance and means. All models of mean components had $\mathrm{R}^{2}$ values near $100 \%$, and then the simple additive-dominant model was considered. Considering the components of variance the model with additive, dominant and environment variance explained the genetic control of maize flowering. The results of the estimated components allowed to conclude that genetic control of earlyness in maize is oligogenic with presence of dominance. Moreover, high values of estimate heritability coefficient indicate the possibility of success with individual phenotypic selection.

Key words: 1 . Zea mays L.; 2. Genetic components; 3. Heritability

$\left({ }^{1}\right)$ Parte da Dissertação de mestrado em Genética e Melhoramento de Plantas, apresentado à ULFA, pelo primeiro autor. Recebido para publicação em 31 de janeiro de 2007 e aceito em 20 de agosto de 2007.

$\left({ }^{2}\right)$ Doutorando do programa de Pos-graduação em Genética e Melhoramento de Plantas da UFLA, DBI/UFLA, Caixa Postal 3037, 37200-000 Lavras-(MG). E-mail: joseluis_li@yahoo.com.br. Apoio financeiro: CNPq.

$\left({ }^{3}\right)$ Departamento de Biologia da UFLA, DBI/UFlA, Lavras-(MG), E-mail: cansouza@ufla.br (*) Autor correspondente. magnoapr@ufla.br

$\left({ }^{4}\right)$ Mestrando do programa de Pós-graduação em Genética e Melhoramento de Plantas da UFLA, DBI/UFLA, Lavras-(MG). E-mail: juarez@posgrad.ulfa.br 


\section{INTRODUÇÃO}

O milho tem sido cultivado em quase todo o território brasileiro. A semeadura ocorre em praticamente todos os dias do ano e nas mais diferentes condições ambientais e de manejo. Dessa forma, são necessárias várias cultivares para atender às necessidades dos produtores, as quais diferem em um conjunto de caracteres, dentre os quais podem ser citados: ciclo, produtividade, tolerância à pragas e doenças e adaptação a diferentes regiões (SANGOI et al., 2002).

Entre os diversos caracteres que estão envolvidos na escolha de uma cultivar de milho, o ciclo é de fundamental importância. Há condições em que as cultivares mais tardias são as preferidas, entretanto, há várias outras condições em que as cultivares precoces são as desejáveis.

Visando conhecer o controle genético do florescimento em milho, alguns trabalhos foram realizados. Segundo ColASANTI et al. (1998), a transição da fase vegetativa para reprodutiva é realizada pelo gene indeterminado 1 (id1), localizado no cromossomo 1 , próximo ao gene Bz2, que condiciona a coloração dos grãos. Usando a tecnologia de marcadores moleculares, KOESTER et al. (1993) identificaram que o número de dias necessário para atingir o florescimento é controlado por locos de caráter quantitativo (Quantitative Trait Loci- QTL), situado no cromossomo 1, próximo ao centrômero.

Para o estudo de controle genético do florescimento em milho, além de estudos efetuados com base em marcadores moleculares, podem ser empregados os procedimentos de genética quantitativa, com a obtenção das estimativas dos componentes de médias e variância. Para isso deve ser entendido que o ciclo da cultura pode ser dividido em duas fases. A primeira corresponde ao período do plantio ao florescimento, denominado fase vegetativa, e a segunda, do florescimento ao ponto de maturidade fisiológica, denominada fase reprodutiva. Dois métodos podem ser empregados para avaliar a precocidade de uma cultivar. O número de dias para a ocorrência da inflorescência masculina é a soma térmica obtida por meio do somatório das temperaturas da semeadura ao início do florescimento (Russell e Stuber, 1985).

Avaliando o número de dias necessário para atingir o florescimento em quatro linhagens de milho, em um dialelo completo, Lopes et al. (1995), concluíram que o caráter é controlado por pelo menos três genes ou blocos gênicos. Resultados semelhantes aos obtidos por HaLLAUER (1965). Já GIESBRECHT (1960) observou valores variando de dois a dezenove genes.
Em termos de efeitos gênicos, Hallauer (1965) apresenta em seu trabalho que o caráter possui maior importância de efeitos gênicos aditivos, e que a dominância possui valor igual a zero, ou valor positivo muito pequeno. Resultados semelhantes aos observados por GIESBRESCHT (1960). Entretanto, os resultados verificados por AJALA (1992) mostram que tanto a ação gênica aditiva como a não-aditiva foram importantes para explicar o caráter florescimento em milho.

Tudo indica que o florescimento é um caráter quantitativo, sendo possível a seleção de genótipos com ciclo precoce ou tardio. Contudo, a estimativa da herdabilidade no sentido restrito por LOPES et al. (1995) foi relativamente baixa $(37,67 \%)$, visto que a seleção com base no fenótipo seria pouco eficaz. Resultados semelhantes aos obtidos por RoOD e MAJOR (1981) e WARNER (1952).

Embora a duração do ciclo de uma planta de milho tenha importância enorme e os melhoristas dediquem sua atenção na seleção, estudos a respeito do controle genético deste caráter em condições de clima tropical são escassos, especialmente envolvendo a soma térmica. Conseqüentemente, este estudo visa obter informações a respeito do controle genético da exigência térmica para o início do florescimento em milho.

\section{MATERIAL E MÉTODOS}

O experimento foi desenvolvido na área experimental do Departamento de Biologia da Universidade Federal de Lavras (DBI/UFLA). Foram utilizadas duas linhagens de milho contrastantes para o início do florescimento. A partir dessas duas linhagens foram obtidas as gerações $F_{1}, F_{2}, R C_{1}$ e $R C_{2}$.

Os genitores e as populações foram avaliados no delineamento de blocos casualizados, com duas repetições. A semeadura foi realizada na safra 2005/ 2006. As parcelas foram constituídas de três linhas de quatro metros de comprimento para as linhagens, duas linhas de quatro metros na geração $F_{1}$ e oito linhas de quatro metros nas demais gerações. $O$ espaçamento foi de $50 \mathrm{~cm}$ entre linhas, e em todas as populações foi empregada uma densidade equivalente a 60.000 plantas por hectare.

Para cada planta obteve-se o número de dias para o início do florescimento masculino e feminino, a partir da semeadura. Considerou-se a data de florescimento masculino quando as anteras iniciavam a liberação de pólen, e o feminino, quando nas inflorescências ocorriam os primeiros estilos-estigmas visíveis. Anotou-se o ponto médio do início do 
florescimento masculino e feminino e, posteriormente, foi estimado o somatório dos graus-dia por meio da expressão apresentada por SILVA et al. (2001).

$$
G D=\sum_{i=1}^{n}\left(\frac{T \max +T \min }{2}-T b\right)
$$

em que:

GD: valor de graus-dia para cada planta atingir o florescimento;

T max: temperatura máxima diária do ar $\left({ }^{\circ} \mathrm{C}\right)$, em que temperaturas iguais ou maiores que $30^{\circ} \mathrm{C}$ foram consideradas iguais a $30^{\circ} \mathrm{C}$;

T min: temperatura mínima diária do ar $\left({ }^{\circ} \mathrm{C}\right)$, em que temperaturas mínimas iguais ou menores que $10^{\circ} \mathrm{C}$ foram consideradas $10^{\circ} \mathrm{C}$;

$\mathrm{Tb}$ : temperatura base da cultura $\left({ }^{\circ} \mathrm{C}\right)$, sendo a temperatura-base adotada para a cultura do milho de $10^{\circ} \mathrm{C}$, segundo recomendação feita por SILVA et al. (2001).

Os valores da soma térmica foram submetidos à análise da variância. Os componentes de média foram estimados utilizando o método dos quadrados mínimos ponderados (Rowe e Alexander, 1980; MATHER e JinKs, 1984), considerando o seguinte modelo: $\hat{\beta}=\left(C^{\prime} N S^{-1} C\right)^{-1}\left(C^{\prime} N S^{-1} Y\right)$, em que, $\hat{\beta}$ é vetor dos parâmetros; $C$ matriz do modelo, sendo constituída da média geral, efeito aditivo e efeito de dominância, dentro de cada geração; $N$ matriz do número de plantas avaliadas dentro de cada geração; $S$ matriz das variâncias associadas às gerações e $Y$ é vetor dos valores médios observados nas gerações (RAMALHo et al., 1993). As estimativas foram obtidas com auxílio do software Mapgen (FerReira e ZAMBALDE, 1997).

Os componentes de variância foram estimados utilizando o método dos quadrados mínimos ponderados interativos (Rowe e Alexander, 1980; MATHER e JINKS, 1984), considerando o seguinte modelo:
$\hat{\beta}=\left(C^{\prime} N C\right)^{-1}\left(C^{\prime} N Y\right)$,em que, $\hat{\beta}$ é o vetor dos parâmetros; $C$ é a matriz do modelo, sendo constituída pela variância aditiva, dominante e ambiental dentro de cada geração; $N$ é matriz dos graus de liberdades associados a cada população e $Y$ é vetor das variâncias observadas dentro de cada população (RAMALHO et al., 1993). A obtenção das estimativas foi realizada com auxílio do software Mapgen (FERREIRA e ZAMbALDE, 1997).

Foram obtidas as estimativas da herdabilidade no sentido amplo e restrito, com os respectivos erros associados e o grau médio de dominância, utilizando as expressões descritas por RAMALHo et al. (1993). Para a estimação do número de genes envolvidos no controle do caráter, foi utilizada a expressão proposta por BURTON (1951).

\section{RESULTADOS E DISCUSSÃO}

Como esperado, as linhagens diferiram na exigência calórica para o início do florescimento, ou seja, em precocidade. A diferença entre as médias dos dois genitores foi de 86,4 graus-dia (Tabela 1). Considerando os graus-dia médios, esse valor é equivalente a diferença de tempo para atingir o florescimento de 7 dias. Magnitude essa, semelhante às observadas em outros trabalhos de estudo de florescimento (HALlAUER, 1965; LoPEs et al., 1995).

As linhagens demoraram um pouco mais para emergir, contribuindo para o aumento na exigência calórica até o início do florescimento e devem ter colaborado, em parte, para que a média da $F_{1}$ e demais gerações fosse inferior ao de ambos os genitores. Esse fato está associado diretamente aos efeitos da depressão por endogamia na germinação e emergência. Segundo Hallauer (1990), tal fenômeno é responsável por um aumento no ciclo vegetativo da planta de milho, na ordem de $6,8 \%$.

Tabela 1. Número de indivíduos avaliados em cada população, com as médias e variâncias em graus-dia, obtidos na safra 2005/06, em Lavras (MG)

\begin{tabular}{lcccc}
\hline População & Número de Plantas & Média & Erro-padrão & Variância \\
\hline $\mathrm{P}_{1}$ & 32 & 924,13 & $\pm 4,63$ & 686,32 \\
$\mathrm{P}_{2}$ & 27 & 1010,49 & $\pm 5,38$ & 783,33 \\
$\mathrm{~F}_{1}$ & 17 & 838,29 & $\pm 7,34$ & 916,5 \\
$\mathrm{~F}_{2}$ & 172 & 849,67 & $\pm 3,78$ & 2459,85 \\
$\mathrm{RC}_{1}$ & 130 & 865,85 & $\pm 3,92$ & 1997,91 \\
$\mathrm{RC}_{2}$ & 185 & 877,08 & $\pm 3,05$ & 1721,12 \\
\hline
\end{tabular}


Foram avaliados vários modelos na obtenção dos componentes de média (Tabela 2). Observa-se que, em todos os modelos, o ajustamento foi bom, $\mathrm{R}^{2}$ (coeficiente de determinação) superior a $99 \%$. Nessa situação, a melhor opção é utilizar o modelo mais simples, isto é, sem os componentes da interação. Infere-se desse modo que, o modelo sem epistasia é suficiente para explicar a variação observada. Nesse modelo, tanto o efeito aditivo (a) como de dominância (d) foram diferentes de zero, no sentido de reduzir a soma térmica, ou seja, no sentido de maior precocidade. Observou-se também que, a magnitude do componente de dominância foi quase 5 vezes maior que o efeito aditivo (Tabela 3 ), corroborando os resultados obtidos por ROOD e MAJOR (1981).

Tabela 2. Modelos dos componentes de média avaliados no estudo do controle genético do florescimento em milho

\begin{tabular}{lc}
\hline Modelos & $\mathrm{R}^{2}(\%)$ \\
\hline$m, a, d$ & 99,98 \\
$m, a, d, i$ & 99,98 \\
$m, a, d, i, j$ & 99,99 \\
$m, a, i, j$ & 99,99 \\
$m, a, d, i, j, l$ & 100,00 \\
\hline
\end{tabular}

$m$ : média geral; $a$ : efeito aditivo; $d$ : efeito de dominância; $i$ : interação aditiva $\mathrm{x}$ aditiva; $j$ : interação aditiva $\mathrm{x}$ dominante; $l$ : interação dominante $\mathrm{x}$ dominante.

Tabela 3. Resultado do teste de escala conjunta para o caráter florescimento em milho envolvendo os parâmetros $\mathrm{m}$, a e d, seus respectivos erros-padrão e valor do $R^{2}$

\begin{tabular}{lcc}
\hline Parâmetros & Estimativa & Erro-padrão \\
\hline$m$ & 954,491 & $\pm 14,963$ \\
$a$ & $-30,478$ & $\pm 14,5807$ \\
$d$ & $-166,577$ & $\pm 35,798$ \\
R2 & 99,98 & - \\
\hline
\end{tabular}

As estimativas dos componentes de variância estão apresentadas na tabela 4. É necessário salientar que, houve bom ajustamento ao modelo adotado $\left(R^{2}\right.$ $>99 \%$ ). A estimativa da variância de dominância foi inferior à variância aditiva (Tabela 4). Segundo BERNARDO (2002), o método dos quadrados mínimos tende a minimizar a variância de dominância, ou seja, os valores são subestimados.

As herdabilidades tanto no sentido amplo quanto no sentido restrito podem ser consideradas altas. Não há relatos na literatura de estimativas de coeficiente de herdabilidade da exigência térmica para o início do florescimento em milho, ou seja, herdabilidade calculada com os valores obtidos do somatório da exigência térmica da semeadura ao início do florescimento. Os resultados tornam-se mais seguros com a exigência térmica, na comparação entre diferentes ambientes, pois a variação do período entre a semeadura e o início do florescimento está relacionada com a exigência térmica e não com o número de dias. As informações de herdabilidade constatadas na literatura referem-se ao número de dias para o início do florescimento (Hallauer e Miranda FILHO 1982; LOPES et al., 1995).

Tabela 4. Estimativas dos componentes de variância e seus respectivos erros-padrão e valor do $R^{2}(\%)$, herdabilidade no sentido amplo e restrito obtido para o caráter florescimento em milho

\begin{tabular}{lcc}
\hline Parâmetros & Estimativa & Erro-padrão \\
\hline$\sigma_{A}^{2}$ & 1200,66 & $\pm 428,91$ \\
$\sigma_{D}^{2}$ & 486,91 & $\pm 294,57$ \\
$\sigma_{e}^{2}$ & 772,27 & $\pm 88,35$ \\
$h_{a}^{2}$ & 68,61 & $\pm 9,80$ \\
$h_{r}^{2}$ & 48,81 & $\pm 20,30$ \\
$\mathrm{R}^{2}(\%)$ & 99,82 & - \\
\hline
\end{tabular}

A estimativa do grau médio de dominância de 0,90 confirmou a importância da dominância na expressão do caráter. A existência da dominância também ficou evidenciada pela distribuição assimétrica dos valores da soma térmica das plantas na geração $F_{2}$ (Figura 1). Devido ao desequilíbrio de ligação, as estimativas da variância aditiva, variância de dominância e o grau médio de dominação podem estar viesados (MATHER e JINKS, 1984).

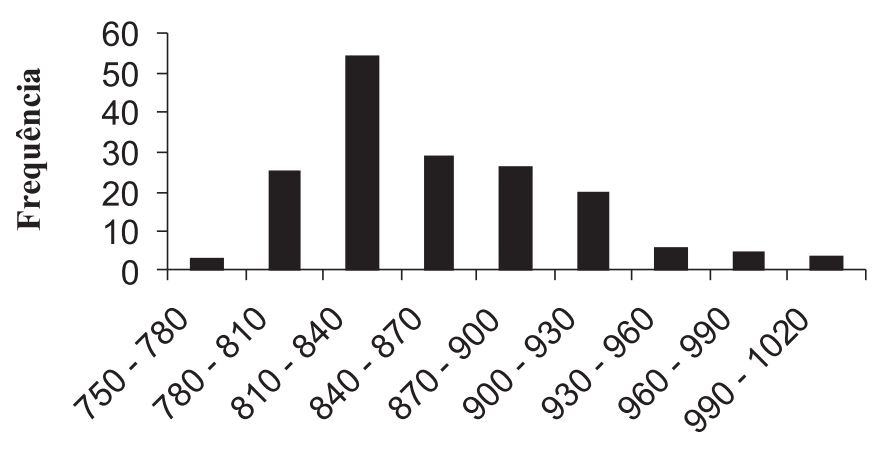

\section{Soma térmica}

Figura 1. Distribuição de freqüência dos indivíduos avaliados na população $\mathrm{F}_{2}$. 
A estimativa do número de genes envolvidos no controle genético da exigência térmica foi de 8,4. Esse resultado indica que o caráter possui controle oligogênico, sendo semelhantes a outros resultados constantes na literatura (LOPES et al., 1995; KOESTER et al., 1993).

\section{CONCLUSÃO}

A soma térmica como medida da precocidade em milho é oligogênica, com a presença de dominância e estimativa de herdabilidade que possibilita inferir sucesso com a seleção massal para o caráter.

\section{AGRADECIMENTOS}

Os autores agradecem à FAPEMIG e ao CNPq, pelo apoio financeiro concedido.

\section{REFERÊNCIAS}

AJALA, S. O. Combining ability for maturity and agronomic traits in some tropical maize (Zea mays L.) populations. Tropical Agriculture, Trinidade, v.69, n.1, p.29-33, jan. 1992.

BERNARDO, R. Breeding for quantitative traits in plants, Woodbury, Minnesota, 2002.368p.

BURTON, G. W. Quantitative inheritance in pearl medlet (Penisetum glaucum). Agronomy Journal, Madison, v. 43, n. 9 p. 409-417, Sept. 1951.

COLASANTI, J.; YUAN, Z.; SUNDAREDAN, V. The indeterminate gene encodes a zinc finger protein and regulates a leaf-generated signal required for the transition to flowering in maize. Cell, Cambridge, v.93, n.4, p.593603, May 1998.

CRUZ, C. D.; REGAZZI, A. J.; CARNEIRO, P. C. S. Modelos biométricos aplicados ao melhoramento genético. 3. ed. Viçosa: UFV, 2004. v. 1.

FERREIRA, D.F.; ZAMBALDE, A.L. Simplificação das análises de algumas técnicas especiais da experimentação agropecuária no Mapgen e softwares correlatos. In: CONGRESSO DA SOCIEDADE BRASILEIRA DE INFORMÁTICA APLICADA A AGROPECUÁRIA E AGROINDÚSTRIA, 1., 1997, Belo Horizonte, MG. Anais... Belo Horizonte, 1997. p. 285-291.

GIESBRECHT, J. The inheritance of maturity in maize. Canadian Journal of Plant Science, Ottawa, v.9, n.3, p.675$677,1960$.

HALLAUER, A. R. Method's use in developing maize inbreeds. Maydica, Begamo, v. 35, n. 1, p. 1-16, Jan./ Apr. 1990.

HALLAUER, A. R.; MIRANDA FILHO, J. B. Quantitative genetics in maize breeding. 2. ed. Ames: Iowa State University Press, 1982. 468 p.
HALLAUER, A. R. Inheritance of flowering in maize. Genetics, v.52, n.1, p.129-137, July 1965.

KOESTER, R. P.; SISCO, P. H.; STUBER, C. W. Identification of Quantitative Trait Loci Controlling Days to Flowering and Plant Height in Two Near Isogenics Lines of Maize. Crop Science, Madison, v.33, n.6, p.1209-1216, Nov./Dec. 1993.

LOPES, U. V.; GALVÃO, J. D.; CRUZ, C. D. Inheritance of the flowering time in maize. Pesquisa Agropecuária Brasileira, Brasília, v.30, n.10, p.1267-1271, out. 1995.

MATHER, K.; JINKS, L.L. Introdução à genética biométrica. Ribeirão Preto: Sociedade Brasileira de Genética, 1984. 242p.

RAMALHO, M.A.P.; SANTOS, J.B.; ZIMMERMANN, M.J.O. Genética quantitativa em plantas autógamas: aplicação ao melhoramento de feijoeiro. Goiânia: UFG, 1993. 271p.

ROOD, S. B.; MAJOR, D. J. Inheritance of tillering and floweringtime in early maturing maize. Euphytica, Wageningen, v.30, p.327-334, 1981.

ROWE, K.E.; ALEXANDER, W.L. Computations for estimating the genetic parameters in joint-scaling test. Crop Science, Madison, v.20, n.1, p.109-110, Jan./Feb. 1980.

RUSSELL, W.K.; STUBER, C W. Genotype $x$ photoperiod and genotype $x$ temperature interactions for maturity in maize. Crop Science, Madison, v.25, p.152-158, 1985.

SANGOI, L.; ALMEIDA, M.L.; SILVA, P.R.F. da; ARGENTA, G. Base morfológica para maior tolerância dos híbridos modernos de milho a altas densidades de plantas. Bragantia, Campinas, v. 61, n.2, p. 101-110, 2002.

SILVA, W. C. M.; RICIERI, R. P.; AMORIM, R. C. F.; GRIGOLETO, M. W.; DALLACORT, R. Temperatura do ar e a duração dos estádios fenológicos do milho. In: Anais eletrônicos... Disponível em: http://www.md.cefetpr.br/ grigoleto/artigo1.pdf. > Acesso em 25 set. 2006

WARNER, J.N. A method of estimating heritability. Agronomy Journal, Madison, v.44, p.427-430, 1952. 